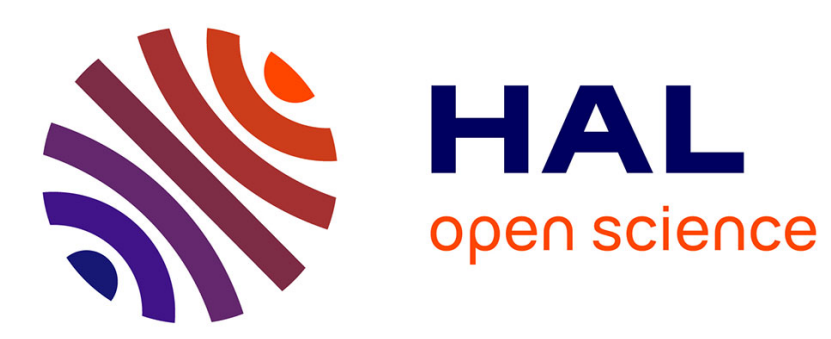

\title{
Confining effect on the bearing capacity of circular footings on a purely cohesive soil
}

\author{
Jean Salençon
}

\section{To cite this version:}

Jean Salençon. Confining effect on the bearing capacity of circular footings on a purely cohesive soil. Comptes Rendus Mécanique, 2002, 330, pp.521-525. 10.1016/S1631-0721(02)01495-X . hal-00111362

\section{HAL Id: hal-00111362 \\ https://hal.science/hal-00111362}

Submitted on 22 Jul 2019

HAL is a multi-disciplinary open access archive for the deposit and dissemination of scientific research documents, whether they are published or not. The documents may come from teaching and research institutions in France or abroad, or from public or private research centers.
L'archive ouverte pluridisciplinaire HAL, est destinée au dépôt et à la diffusion de documents scientifiques de niveau recherche, publiés ou non, émanant des établissements d'enseignement et de recherche français ou étrangers, des laboratoires publics ou privés. 


\title{
Confining effect on the bearing capacity of circular footings on a purely cohesive soil
}

\author{
Jean Salençon \\ École polytechnique, Laboratoire de mécanique des solides, 91128 Palaiseau cedex, France
}

\begin{abstract}
The bearing capacity of axially symmetrical footings acting on a purely cohesive soil foundation contained by a rigid wall at a finite distance is investigated within the framework of the Yield design theory. Following the same tracks as in a preceding paper devoted to strip footings, the analysis is performed by referring to already existing results concerning the bearing capacity of a circular footing on a soil layer with limited thickness. It comes out that the bearing capacity factor determined by Eason and Shield for a rough circular footing on an unlimited soil foundation is increased by a correction factor that increases when the diameter of the container decreases. Comparison with the results obtained for strip footings acting on a purely cohesive soil in the same conditions shows that the confining effect is significantly lower for a circular footing than for a strip footing.
\end{abstract}

soils / bearing capacity / confinement / circular footing / yield design

\section{Effet du confinement sur la capacité portante d'une fondation circulaire sur un sol purement cohérent}

Résumé On étudie la force portante d'une fondation superficielle circulaire chargée axialement sur un demi-espace limité horizontalement par une enceinte circulaire rigide. On se place dans le cadre de la théorie du calcul à la rupture. Comme dans un article précédent, l'analyse est menée à partir des résultats déjà existants pour la portance d'une fondation circulaire sur une couche de sol d'épaisseur limitée. On montre ainsi que le facteur de capacité portante déterminé par Eason et Shield pour une fondation circulaire rugueuse sur un sol illimité doit, dans le cas présent, être multiplié par un facteur qui croit quand le diamètre de l'enceinte rigide diminue. La comparaison de ces nouveaux résultats avec ceux obtenus pour les semelles filantes dans les mêmes conditions montre que l'effet de confinement est beaucoup moins sensible pour une fondation circulaire.

sols / calcul à la rupture / confinement / fondation circulaire / force portante

\section{The problem under investigation}

The paper is concerned with the theoretical evaluation of the bearing capacity of a rigid axially symmetrical footing under axial loading, acting on a homogeneous soil foundation with infinite thickness. The diameter of the footing being denoted $B=2 b$, the soil foundation is assumed to be limited in all horizontal directions at a distance $L$ from the edge of the footing by rigid walls. The contact between the 
footing and the soil on the one side and between the soil and the rigid walls on the other is assumed to be perfectly rough. As a matter of fact a similar problem has been studied in a preceding paper [1] where the analysis was restricted to strip footings while the soil foundation could be either purely cohesive or cohesive and frictional. The expected confining effect due to the limited width of the soil foundation was assessed in the form of a correction factor to be applied to the classical bearing capacity factors in Terzaghi's formula, a function of $L / b$.

The goal of the paper is now, restricting the analysis to a purely cohesive soil foundation, to assess the correction factor in the case of a circular footing and to compare it with the results for a strip footing. Applications of this analysis are expected in the design of soil structures and in the interpretation of reduced scale experiments.

\section{Theoretical framework}

The theoretical framework is given by the theory of Yield Design [2] or Limit Analysis. The foundation soil is assumed isotropic and purely cohesive with cohesion $c_{\mathrm{u}}$ and it is characterised by a Tresca strength criterion.

The implementation of the theory will mainly follow the same tracks as for the plane problems examined in [1], with the additional assumption of the Haar-Karman hypothesis [3]. The kinematic approach with virtual velocity fields being obtained through the method of characteristics will provide upper bound estimates for the correction factor.

One important result obtained in the plane case was to show that upper bound estimates for the assessment of the confining effect due to the limited horizontal width of the soil foundation could be conveniently obtained by revisiting classical solutions to the problem of the bearing capacity of a surface footing on a soil layer of limited thickness. The present analysis is organised in just the same way.

\section{Circular footing on a purely cohesive soil}

The considered circular footing is with axis $O x$. The axial force acting on the footing is denoted by $F$ and the bearing capacity is: $p_{\mathrm{ult}}=F / \pi b^{2}$. From dimensional analysis it comes out that

$$
p_{\mathrm{ult}}=c_{\mathrm{u}} K_{c}^{\prime}(L / b) N_{c}^{\prime},
$$

where $N_{c}^{\prime}=6.05$ is the bearing capacity factor for a rough circular footing on an unlimited soil foundation.

\subsection{Unlimited soil foundation}

The theoretical determination of $N_{c}^{\prime}$ within the framework of Limit Analysis was given by Eason and Shield [4] using the equations of axially symmetric plastic flow with the hypothesis of Haar and von Karman. The corresponding mesh of characteristic lines is sketched in Fig. 1 adapted from the original paper. With $w$ denoting the length of the uplifted wave $A D$, the geometric ratios of this mesh are $w / b=C_{c}^{\prime}=0.88$ and $B / d=2.34$. For the use of this mesh as a static approach, the stress field was extended in the whole bulk of soil using a method similar to the method given by Bishop [5] in the plane strain case (Fig. 1). For the kinematic approach, an axially symmetric velocity field was constructed: the footing is given a vertical virtual velocity and the volume defined by $A B A^{\prime}$ moves as a rigid body with the same velocity; the region defined by $A B C D$ is deformed with no volume change and the rest of the soil foundation beneath $D C B C^{\prime} D^{\prime}$ is motionless.

\subsection{Limited soil foundation}

\subsubsection{Static approach}

Obviously a statically admissible stress-field respecting the Tresca yield criterion is obtained in the bulk of soil within the container, whatever $L / b \geqslant 0$, through considering the restriction of the stress-field in 

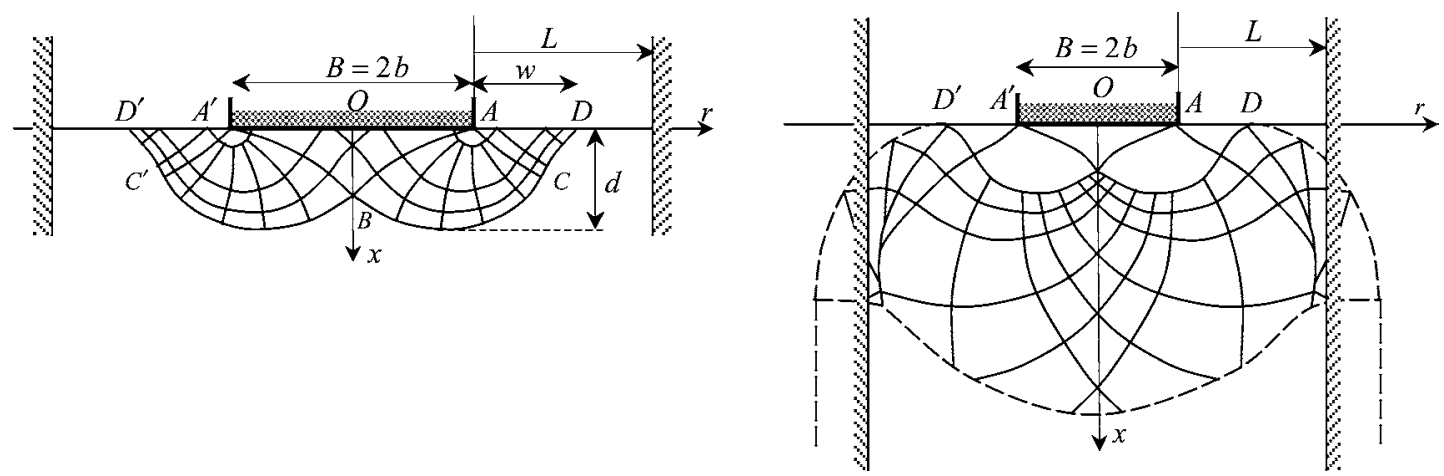

Figure 1. Eason and Shield kinematical and static solution [4].

Fig. 1 within the domain $r \leqslant b+L$. Regarding the friction condition at the interface between the wall and the soil $(r=b+L)$, it must also be checked that the normal stress acting on the rough wall is compressive everywhere. Such a verification is not as easy as in the plane case [1] where the extension of Prandtl's stress-field by Shield's method [7] could be used, thus providing an explicit stress field. In the present case we assume that, having checked the condition at the interface, we may state that:

$$
\forall L / b \geqslant 0, \quad K_{c}^{\prime}(L / b) \geqslant 1 .
$$

The practical significance of Eq. (2) is that the effect of confinement always results in an increase of the bearing capacity of the footing.

\subsubsection{Kinematic approach}

- $L / b \geqslant C_{c}^{\prime}$

This kinematic approach is obviously still valid when the soil foundation is limited by a rough rigid wall at a distance $L$ from the edge of the footing greater than the width of the uplifted wave: $L / b \geqslant C_{c}^{\prime}=0.88$. Taking Eq. (2) into account it follows, that:

$$
\forall L / b \geqslant C_{c}^{\prime}=0.88, \quad K_{c}^{\prime}(L / b)=1 .
$$

- $0 \leqslant L / b<C_{c}^{\prime}=0.88$

The investigation of the range $0 \leqslant L / b<C_{c}^{\prime}=0.88$ follows the same path of reasoning as for the strip footing [1]. It refers to the solution to the bearing capacity problem for an axially symmetric footing acting on a soil layer of limited thickness $h$ where the bearing capacity appears as a function of $B / h$ and is written in the form

$$
p_{\mathrm{ult}}=c_{\mathrm{u}} F_{c}^{\prime}(B / h) N_{c}^{\prime}
$$

with $F_{c}^{\prime}(B / h)$ a non-dimensional correction factor.

Salençon and Matar [6] made the analysis of that problem using the equations of axially symmetric plastic flow with the Haar-Karman hypothesis in order to determine $F_{c}^{\prime}(B / h)$. They constructed the network of characteristic lines as presented in Fig. 2, starting from the data on the stress free surface and taking into account the perfectly rough contact condition at the interfaces between the soil layer and the footing on the one side and between the soil layer and the bedrock on the other. The width of the uplifted wave is again denoted by $w$. This network starts with the same fan of characteristic lines at point $A$ as in Fig. 1 . Due to the form of the equations along the characteristic lines in this case (e.g. [7]) where the distance to the $O x$ axis appears explicitly, this fan is not self-similar with respect to $A$ as it used to be in the plane 


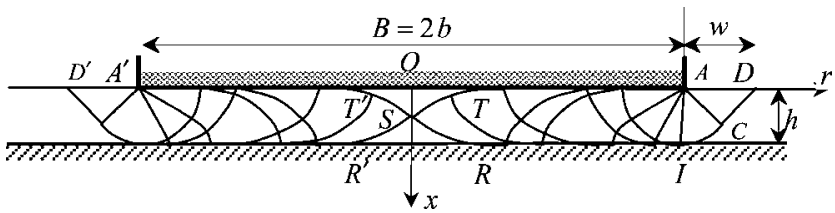

Figure 2. Salençon and Matar solution [6].

strain case and therefore the ratio $w / h=\lambda_{c}^{\prime}$ is now dependent on $B / h$ when $B / h>2.34$. Although they were not published in the paper we are referring to, the values of the geometrical ratios $B / h>2.34$ and $w / b$ corresponding to each other in these networks had obviously been computed and are still available: they are presented in Fig. 3. From this chart we derived $\lambda_{c}^{\prime}$ as a function of $B / h$ to be used later on. The corresponding value of $p_{\text {ult }}$ is obtained as a function of $B / h>2.34$ and yields $F_{c}^{\prime}(B / h)$ in Eq. (4).

For the interpretation of this solution as a static approach the extension of the stress field in the volumes defined by $T^{\prime} S T, R^{\prime} S R$ and outside $I C D$ is made in the same way as in the strip footing case. In order to make it a kinematic approach, an axially symmetric velocity field was numerically constructed for different values of $B / h>2.34$, following the same tracks as in the infinite case by Eason and Shield, applying the equations for the velocity along the characteristic lines. The volume defined by $T^{\prime} S T$ moves as a rigid body with the same vertical velocity as the footing; the volume defined by $R^{\prime} S R$ is motionless as well as the volume outside $I C D$; the rest of the soil layer is deformed with no volume change.

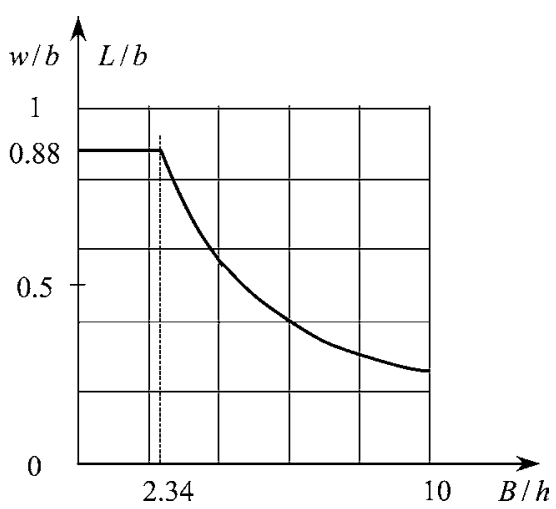

Figure 3. Geometric ratios in Salençon and Matar solution.

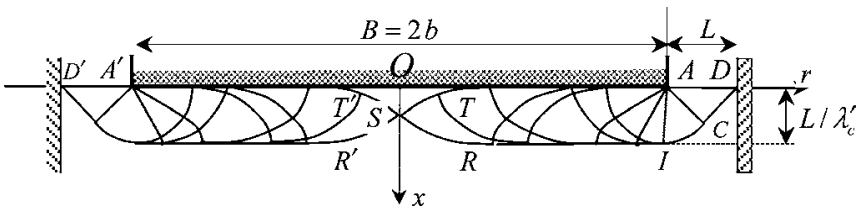

Figure 4. Proposed solution for assessing the confining effect.

The chart in Fig. 3 now makes it possible to deal with the problem we are presently investigating. Given $L / b<C_{c}^{\prime}=0.88$, the corresponding value of $B / h$ is determined from Fig. 3, for which the mesh of characteristic lines in Fig. 2 fits exactly the horizontal width of the soil foundation (Fig. 4). For a kinematic approach, the velocity field determined in the corresponding case for the soil layer is considered and extended assuming the soil mass to be motionless for $x \geqslant h$. It follows that an upper bound estimate is obtained for $K_{c}^{\prime}(L / b)$ in the form:

$$
K_{c}^{\prime}(L / b) \leqslant F_{c}^{\prime}(B / h)=F_{c}^{\prime}\left[2 \lambda_{c}^{\prime}(L / b)^{-1}\right]
$$

where $L / b$ and $B / h$ are linked to each other according to the chart in Fig. 3. This upper bound is presented in Fig. 5. It appears that the increase of the bearing capacity due to this confining effect remains very small for realistic values of $L / b$ in the case of circular footings. 
Figure 5. Correction factors for the confining effect.

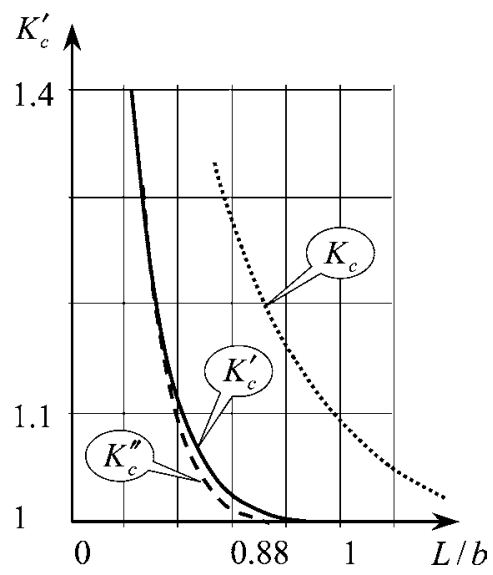

\section{Comparing axially symmetrical footings with strip footings}

The upper bound for $K_{c}(L / b)$ obtained in the case of the strip footing is also presented in Fig. 5 . Comparison shows immediately that the confining effect due to the rigid walls is, by far, less important for the axially symmetrical footing than for the strip footing for the same value of the non-dimensional geometric ratio $L / b$.

From a physical viewpoint this is no big surprise. As a matter of fact one may expect the confining effect to be roughly correlated to the ratio of the volumes of soil that are concerned with the collapse phenomenon under the footing and up to the walls, respectively. Following this track a crude estimate for $K_{c}^{\prime}(L / b)$ can be derived from $K_{c}(L / b)$ in the form:

$$
K_{c}^{\prime \prime}(L / b)=K_{c}\left[(1+L / b)^{2}-1\right] .
$$

This heuristic estimate for $K_{c}^{\prime}(L / b)$ is drawn in Fig. 5: the comparison with the upper bound for $K_{c}^{\prime}(L / b)$ in Eq. (5) is quite interesting.

The analysis described in the preceding sections confirms that for axially symmetrical footings the assessment of the confining effect due to the limited horizontal width of the soil foundation can be conveniently made by revisiting classical solutions to the problem of the bearing capacity on a soil layer of limited thickness in the same way as for strip footings.

\section{References}

[1] J. Salençon, The influence of confinement on the bearing capacity of strip footings, C. R. Mecanique 330 (2002) 319-326.

[2] J. Salençon, An introduction to the yield design theory and its applications to soil mechanics, Eur. J. Mech. A 9 (5) (1990) 477-500.

[3] A. Haar, Th. von Karman, Zur Theorie der Spannungszustände in plastischen und Sandartigen Medien, Nachr. Ges. Wiss. Göttingen, Math.-Phys. Kl. (1909) 204-218.

[4] G. Eason, R.T. Shield, The plastic indentation of a semi-infinite solid by a perfectly rough circular punch, Z.A.M.P. 11 (1960) 33-43.

[5] J.F.W. Bishop, On the complete solution to problems of deformation of a plastic rigid material, J. Mech. Phys. Solids 2 (1) (1953) 43-53.

[6] J. Salençon, M. Matar, Capacité portante des fondations superficielles circulaires (Bearing capacity of axially symmetrical shallow foundations), J. Mec. Th. Appl. 1 (2) (1982) 237-267.

[7] R.T. Shield, Plastic potential theory and Prandtl bearing capacity solution, J. Appl. Mech. Trans. ASME 21 (1954) 193-194. 